\title{
REFLEXÃO SOBRE \\ A NORMATIZAÇÃO \\ DO PORTUGUÊS \\ DE MOÇAMBIQUE
}

\section{REFLEXIÓN SOBRE LA NORMALIZACIÓN DE LA LENGUA PORTUGUESA DE MOZAMBIQUE}

REFLECTIONS ON THE STANDARDIZATION OF THE MOZAMBICAN PORTUGUESE

\author{
LANGUAGE
}

\author{
Diocleciano Nhatuve* \\ Universidade do Zimbabwe \\ Universidade de Coimbra
}

\begin{abstract}
RESUMO: Neste artigo discute-se a necessidade de padronização do Português de Moçambique para promover a autoestima dos falantes moçambicanos e facilitar os estudos desta variante. Para alguns autores, a padronização deve depender da descrição exaustiva dos diferentes aspectos linguísticos e discursivos; para outros, a variante moçambicana já apresenta características próprias suficientes para o início do processo da normatização . É dentro deste quadro teórico e à luz da sociolinguística variacionista, a partir de dados que revelam as marcas próprias desta variante em diferentes áreas da língua, que se propõe o início de um processo gradual da padronização considerando os aspectos que não mudam com a escolarização.

PALAVRAS-CHAVE: Português de Moçambique. Aspectos marcantes. Variação. Normatização.
\end{abstract}

RESUMEN: En este artículo se discute la necesidad y la posibilidad de la normalización de la lengua portuguesa de Mozambique para promover la autoestima de los hablantes mozambiqueños y facilitar los estudios de esta variante. Para algunos autores, la normalización debe depender de la descripción detallada de los diferentes aspectos lingüísticos y discursivos, para otros, la variante del Portugués de Mozambique ya presenta características suficientes para el inicio de su proceso de normalización. Es dentro de este marco teórico y a la luz de la sociolingüística de variantes que, considerando los datos del Portugués de Mozambique, los cuales muestran las marcas propias de esta variante en diferentes áreas de lengua, se propone el inicio de un proceso gradual de estandarización teniendo en cuenta los aspectos que permanecen, en la educación.

PALABRAS CLAVE: Portugués de Mozambique. Aspectos excepcionales. Variación. Normalización.

ABSTRACT: This article discusses the need of the standardization of the Portuguese language spoken in Mozambique to foster selfesteem in Mozambican Portuguese speakers and to ease researches on this variety. Some authors argue that the standardization must depend on the exhaustive description of the different linguistic and discursive aspects; others claim that the Mozambican variant of Portuguese already has sufficient characteristics to start prescription processes. It is within this theoretical framework and in the light of the variationist sociolinguistics that, considering data of the Mozambican Portuguese, which reveals its characteristics

* Leitor de língua portuguesa na Universidade do Zimbabwe. Doutorando em Língua Portuguesa: Investigação e Ensino (UniversidadedeCoimbra).E-mail:djrnhatuve@gmail.com. 
in different usages of the language, we argue that it is necessary to begin a gradual standardization process that takes into consideration the unchanging aspects as a result of a teaching and learning processes.

KEYWORDS: Mozambican Portuguese language. Remarkable aspects. Variation. Standardization.

\section{INTRODUÇÃO}

Todas as línguas vivas estão sujeitas às condições impostas pela dinâmica sociolinguística de um determinado contexto. Por força da história, o Português é atualmente falado em várias regiões do mundo, contando já com duas normas reconhecidas, a do Português Europeu (PE) e a do Português Brasileiro (PB). Em cada local, dado que os falantes aprendem e apreendem o Português

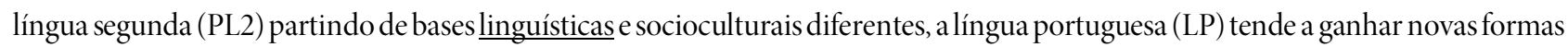
linguísticas e novas formas de uso. Linguisticamente, as mudanças a que a LP se tem sujeitado enquadram-se no fenômeno de variação “[...] que pode ser estudada e descrita” (FERREIRA et al., 1996).

Neste contexto, o presente trabalho constitui um contributo na discussão sobre a normatização do Português de Moçambique (PM), num momento em que, para além de se demonstrar a impossibilidade de os moçambicanos falarem o PE, reconhece-se que o PM, devido ao contexto sociolinguístico marcado pelo uso do Português como língua franca e de instrução, pelo seu encontro com outras línguas moçambicanas de origem bantu e por realidades socioculturais heterogêneas - dando lugar aos fenômenos de transferência e interferência linguísticas - adquiriu formas sintáticas, morfológicas, lexicais, fonéticas e fonológicas próprias, distanciando-se sobremaneira do PE oficialmente ensinado na escola. Este distanciamento, entretanto, resulta de um processo sociolinguístico de apropriação do Português pelos nacionais de Moçambique, processo ao qual autores como Firmino (2008) designam de nativização ${ }^{1}$ do Português. Aliás, o Português em Moçambique é uma língua não nativa, com estatuto de língua oficial e de instrução, no entanto, a sua aquisição, para a maioria dos moçambicanos, depende do processo formal de ensino-aprendizagem. Nos dias de hoje, segundo os dados do Instituto Nacional de Estatística (2015), cerca de 49.9\% da população (maioritariamente adultos e idosos) é analfabeta, o que implica, ao mesmo tempo, que não sabe falar nem escrever em Português.

Desta feita, partindo dos dados disponíveis sobre o léxico, a morfossintaxe e a regência do PM apresentados por diferentes autores (BRITO, 2002; FIRMINO, 2008; GONÇALVES, 2010; JOHN-AND, 2010; NHATUVE e FONSECA, 2013; entre outros), pretendese defender o início da normatização do PM, devendo ser um processo contínuo até se atingir a descrição e prescrição abrangentes. A escolha deste tema tem a ver com a necessidade da realização de trabalhos científicos e acadêmicos que legitimem os falares típicos da nação, o que promoverá a autoestima linguística dos falantes moçambicanos de Português ${ }^{2}$. Para além disto, a normatização do PM constitui um aspecto prioritário e pertinente para a realização de qualquer trabalho relacionado com a gramática do PM. Assim, poder-se-á dirimir as inconveniências de se estudar o PM com base no $\mathrm{PE}^{3}$, estudos que acabam sendo somente de caráter contrastivo (GONÇALVES, et al., 1998; GONÇALVES, 1998), focalizando o errado e o certo.

A variação do Português pode ser regional (diatópica, geolinguística, dialetal), histórica (diacrónica), social (diastrática) ou situacional (diafásica) (FERREIRA et al., 1996, p. 479-481). Desta forma, dentre as variedades do Português que se verificam num determinado território,

[...] uma delas, por diversas razões, pode adquirir maior prestígio e impor-se como norma ou língua padrão. Os fatores que determinam essa escolha são normalmente sociopolíticos, históricos, comunicativos e até pedagógicos. Nada, de ponto de vista estritamente linguístico, leva a que uma determinada variedade seja preferida como norma de uma língua. Só fatores extralinguísticos influem nessa escolha (FERREIRA et al., 1996, p. 483).

\footnotetext{
${ }^{1}$ O termo nativização é usado na perspetiva de Firmino (2008, p.122) para se referir ao "[...] processo de aculturação através do qual uma língua ex-colonial se aproxima do contexto sociocultural de urn país pós-colonial".

${ }^{2} \mathrm{O}$ termo autoestima do falante refere-se ao uso da língua, em diferentes contextos sociais, sem receio do falante de ser criticado porque fala de maneira diferente da que está prevista no Português Europeu (PE); refere-se ao uso da língua e ao reconhecimento da legitimidade do falar moçambicano, independentemente do seu distanciamento em relação ao PE.
}

${ }^{3}$ Com esta expressão, refere-se à prática atual em estudos do PM que consiste em analisar esta variante com base em conhecimentos do PE. 
Perante a situação descrita acerca do fenômeno de variação, em que se destaca o fato de a mudança e a variação linguísticas serem fenômenos que caracterizam as línguas vivas, tomando contornos significativos quando uma determinada língua é falada em vários locais diferentes nos quais não funciona como língua materna (LM), ou seja, em territórios como Moçambique, o Português vai sofrer uma mudança acentuada e mais significativa do que nos territórios onde o idioma é LM. Saliente-se também o fato de na definição de uma norma não serem os aspectos linguísticos aqueles que determinam a escolha de um código como língua padrão. Entretanto, para o caso do Português em Moçambique que, como tem sido reportado e demonstrado, está a registrar variações significativas em áreas essenciais da língua (léxico, morfossintaxe, regência verbal), tendo em conta a ideia de Ferreira et al. (1996), há que se colocar as seguintes questões: épossível ou é necessário criar uma norma do PM? Por quê?

Nesta ordem, o estudo e a reflexão sobre este tema basear-se-ão em vários contributos de linguistas moçambicanos sobre o assunto e em dados do PM apresentados por eles. Estes dados servirão para demonstrar os diferentes aspectos característicos do PM abordagem qualitativa - a partir dos quais se deve iniciar a normatização. Este processo, naturalmente, não deverá simplesmente consistir em considerar todos os aspectos relatados para a prescrição. Deve-se encontrar mecanismos para identificar e selecionar o que, não dependendo do estatuto social ou do nível de escolaridade, é comum à maioria dos falantes - verdadeiras características do PM. Portanto, este trabalho compreende três partes principais: uma diz respeito à discussão sobre os conceitos de variação e normas do Português; a outra é concernente à apresentação de dados ilustrativos dos aspectos do PM extraídos de textos publicados sobre esta variante. E, finalmente, considerando os contributos de autores como Lopes (1997), Gonçalves (2005, 2010) e Dias (2002), discute-se e argumenta-se a favor do início da normatização do PM, na última parte.

\section{VARIAÇÃO E NORMAS DO PORTUGUÊS}

Entre os falantes de uma língua há um conhecimento comum que os permite usar a língua e, mais do que fazer o uso, permite-os distinguir um uso adequado do inadequado (MATEUS; CARDEIRA, 2007, p. 19). Esta capacidade resulta de um reconhecimento de um determinado modo de falar, que é uma linha comum de toda uma comunidade, a norma, o modo de uso da língua que, normalmente, se usa na escola. O Português, tal como se referiu anteriormente, tem duas normas, a norma europeia, originária da LP, e a brasileira, que resultou de fenômenos relacionados com a variação e da necessidade de se valorizar as particularidades do falar brasileiro.

Entretanto, a situação atual da LP em Moçambique desencadeia várias questões no âmbito da política linguística nacional. É que, apesar de se ensinar a norma do PE nas escolas, não se fala um Português que se aproxime daquele padrão. O PM apresenta aspectos que o particularizam sobremaneira. Desta feita, não são descabidas tais questões, tendo em vista um contexto em que a escola reconhece e ensina uma norma que muito se distancia da realidade de seus falantes. A norma não é produto linguístico, nem deve estar totalmente distanciado do falar de todo um povo, embora possa haver algumas diferenças dialetais. Nesse sentido, Mateus e Cardeira (2007) definem uma norma como sendo a "[...] modalidade linguística escolhida por uma sociedade enquanto modelo de comunicação" (2007, p. 21). Mas, como tal escolha é feita? A criação é feita inconscientemente, no e através do uso, e legitimada conscientemente por uma política linguística ${ }^{4}$ favor dessa norma, quer na oralidade, quer na escrita.

A norma pode ser igualmente definida como a "[...] variedade dialetal ou socioletal utilizada no uso da língua em contexto escolar e nos meios de comunicação. Assim, a norma coincide geralmente com a variedade dialetal e socioletal dominante" (MATEUS; VILALVA, 2007, p. 99). Todavia, importa salientar o fato de que, no contexto moçambicano, a norma é a variedade ensinada na escola; no entanto, o Português usado e materializado pelos agentes de ensino-aprendizagem e pela sociedade em geral não é o Português oficialmente ensinado. Está-se perante o dilema norma ideal (Português ideal) - a que está prevista para ser usada - e norma real (Português realizado pelos alunos e sociedade no geral), a qual se sobrepõe esmagadoramente à ideal, a que é objeto de ensino.

${ }^{4}$ Conjunto de intenções e decisões do Governo de um país relativas ao uso oficial de uma ou mais línguas e a determinação da norma-padrão, tanto no que respeita à língua oral como à escrita (as reformas ortográficas são exemplos de ações de política linguística). Faz parte, igualmente, da política linguística a forma de divulgação de uma língua como língua estrangeira ou segunda, de acordo com o contexto em que é ensinada (MATEUS; VILALVA, 2007, p. 99). 
$\mathrm{Na}$ verdade, mesmo não dependente dos aspectos linguísticos, a normatização de uma língua “[...] supõe a produção de instrumentos de normalização linguística, cuja função é descrever a estrutura e o léxico dessa variedade, bem como fixar as regras do seu registro escrito: contam-se entre os mais importantes as gramáticas, os dicionários, os tratados de ortografia e os prontuários ortográficos” (DUARTE, 2000, p. 27).

A questão da LP em Moçambique - o seu estatuto de língua oficial, língua franca e exclusiva do ensino - é resultado de uma política linguística adotada quando da independência do país, e posteriormente documentada na constituição de 1990 (SANTANA, 2010 , p. 58), com objetivos sociopolíticos bem claros e, àquela data, urgentes, como o fomento do ensino-aprendizagem e o uso do Português para salvaguardar a unidade nacional de um povo etnolinguisticamente heterogêneo.

Teria sido impossível que em 25 de Junho de 1975 se tivesse escolhido uma das várias línguas moçambicanas para língua nacional, porque as querelas que traziam fariam decerto perigar a existência do estado uno, teriam impossibilitado a unidade que criamos no seio do nosso partido e impedido as vitórias que já alcançamos na edificação das bases materiais e ideológicas para a construção da sociedade socialista (GANHÃO, 1979 apud FERREIRA, 1987, p. 252).

É certo que tal política teria permitido a realização dos objetivos pretendidos, porém, sob o ponto de vista meramente linguístico, bloqueou significativamente o avanço das línguas bantu com as quais o Português coabita, e retardou os trabalhos de descrição e prescrição dos verdadeiros falares moçambicanos. Aliás, em Moçambique, debate-se, atualmente, com a questão do essencialismo/tradição linguístico/a - atitude que se relaciona com a manutenção e deificação do PE favorecido pela política linguística do movimento de libertação que o adotou como instrumento de comunicação e posteriormente o impôs na sociedade em 1975 (SANTANA, 2010) - e o epocalismo - que remete à língua real falada no Moçambique de hoje.

Efetivamente, nesse país, o Português passou/passa pelo processo de nativização que cimentou as respectivas formas próprias. Neste âmbito, grande número dos aspectos que se salientam como marcas do PM, sobretudo os lexicais, fonéticos, sintáticos e de regências, não mais deve ser interpretado, analisado ou concebido como realizações desviantes, perspectiva de análise da variação linguística que "[...] assume que as variedades não-nativas são realizações imperfeitas de uma variedade nativa, [negando] o estatuto ontológico de uma variedade não-nativa, ao tomá-la não pelo seu próprio direito mas como uma variedade [...] deficiente" (FIRMINO, 2008, p. 123). Para além disto, esta perspectiva não reconhece o caráter dinâmico do Português - sua capacidade de se adaptar a vários contextos sociolinguísticos sem deixar de ser Português, num mundo em que esforços devem ser feitos para promover a educação intercultural (CARNEIRO, 2008).

A LP em Moçambique atingiu, com efeito, um nível ontológico (em áreas de sintaxe, fonética, léxico e regência) e simbólico (nova ideologia linguística em diferentes áreas sociais) que não mais deve ser ignorado. É necessário que seja revista a política linguística, de modo a criar-se uma plataforma de harmonização da norma e o uso do Português, para que o falar moçambicano seja analisado e interpretado não em função de uma outra norma, que sempre desagua na perspectiva desviante do PM, mas em função de prescrições próprias.

É certo que a padronização linguística "[...] compreende vários estágios que vão desde a fase de seleção da norma até à fase da sua codificação em dicionários e gramáticas” (GONÇALVES, 2005, p. 184-196), um processo que é dependente de muitos fatores sociopolíticos. Reconhece-se igualmente que a norma descritiva deve preceder a norma prescritiva e que, no caso de Moçambique, é ainda insignificante o trabalho descritivo do Português sobretudo nas áreas "[...] da fonética, da fonologia e da semântica, assim como sobre as estratégias retóricas e discursivas típicas do PM" (GONÇALVES, 2005). No entanto, não é consensual que se retarde o início do processo de padronização por conta destas lacunas. Parece que as áreas significativamente descritas (sintaxe, regência e léxico) têm uma sólida relação com as que ainda faltam descrever. Portanto, a normatização deve começar com os dados disponíveis e, de uma forma gradual, abranger todas as áreas da língua e desenvolver a norma do PM. Não se deve ter medo de avançar para a definição clara dos aspectos que particularizam esta variante. Uma gramática do PM (normalização) só surgirá a partir do momento em que os falantes, linguistas e o Estado reconhecerem a legitimidade do seu falar; falando, descrevendo e prescrevendo o seu Português, fato urgente e necessário. 


\section{DADOS DO PM}

Nesta secção são apresentados alguns aspectos característicos do PM. Os dados de natureza descritiva, referentes às áreas de léxico, morfossintaxe e regência verbal, foram extraídos de vários estudos efetuados sobre o PM. Na sua maioria, são dados do Português oral (GONÇALVES, 1997; GONÇALVES et al., 1998) e escrito (NHATUVE e FONSECA, 2013; ATANÁSIO, 2002) das zonas urbanas do sul e do norte de Moçambique, recolhidos através de gravações e recolhas de textos. Os principais aspectos apresentados dizem respeito às realizações desviantes ou inovadoras do PM em relação ao PE. Estes dados são meramente ilustrativos das realizações do PM. Não se trata necessariamente de dados a se considerar para a normatização, mas, sim, de tomá-los (dados descritivos do PM existentes) como ponto de partida, devendo-se ponderar quais podem ser considerados como verdadeiras marcas do PM.

Em 2000, na obra Língua Portuguesa: Instrumento de análise, a linguista Inês Duarte, consciente de que a proficiência em Português em Moçambique depende da escolarização, afirmou que "[...] no Português falado pelas camadas mais escolarizadas [...] ocorrem com regularidade fenômenos não detetáveis nem na variedade europeia nem na brasileira [... ]” (DUARTE, 2000, p. 22). Isto ilustra o desencontro entre a vontade de implantar no país a norma do PE e a prática comunicativa dos falantes, esta última que se materializa de forma diferente, embora não o suficiente para se considerar fenômeno de crioulização ${ }^{5}$, mas sim, bastante para se distinguir de qualquer outro modo de falar em Português. Até o momento, os estudos sobre o PM focalizaram três áreas em que se salientam particularidades recorrentes, ainda que haja dificuldades de se definir se se trata de desvios à norma, de manifestações de interlíngua ou de verdadeiras marcas sólidas do PM:

\subsection{LÉXICO}

É na área do léxico que mais se revela o processo de nativização do PM (FIRMINO, 2008, p. 8). Relativamente à formação e introdução dos moçambicanismos - unidades lexicais neológicas do PM resultantes de diferentes processos de renovação e criação lexical - verifica-se que todos os processos têm lugar, podendo-se salientar, por um lado, as palavras que passam de uma modificação parcial (resultando em unidades estruturalmente híbridas), através de uso de afixos do Português em bases de línguas bantu $($ khenhar-khenya $($ Xangana $=$ dar rasteira $)+-$ ar $($ sufixo verbal $)$ ). E, por outro, as palavras que são modificadas em todos os aspectos formais (deletar), independentemente da origem dos morfemas envolvidos. Aliás, a derivação sufixal é que se destaca neste âmbito. Para além de um encontro e fusão do Português com as línguas bantu que se materializa na combinação dos morfemas, uma outra característica da criação de moçambicanismos é o surgimento de novas palavras a partir de outras da LP (exemplo: desconseguir=não conseguir), entre outros.

O uso de moçambicanismos - que na sua maioria ainda não estão dicionarizados - pode ser visto e analisado em três vertentes principais, nomeadamente, como se tratando de uma das estratégias dos falantes para dirimir, por um lado, as suas dificuldades no uso do Português e, por outro, as ineficiências que a LP apresenta na nomeação de algumas realidades moçambicanas, como uma forma consciente ou não de dar características próprias ao PM; ou como uma situação incontornável que a realidade sócioeducativo-linguística impõe aos moçambicanos.

\subsection{MORFOSSINTAXE}

Na área de morfonsintaxe destacam-se cinco subáreas:

\section{a) Concordância}

O fenômeno de concordância no PM é marcado pela concordância variável no interior do sintagma nominal (SN) (exemplos la, 1b, 1c.) (JOHN-AND, 2010; GONÇALVES, 2010; NHATUVE; FONSECA, 2013) e entre o sujeito e o verbo (exemplos 1d, 1e). A

${ }^{5}$ Processo de criação de um crioulo através da fusão de uma língua estrangeira com uma local, resultando num léxico e numa gramática próprios, distante dos idiomas originais. 
tendência é de se usar o gênero e o número não marcados (masculino e singular), independentemente dos traços morfossintáticos do núcleo nominal. Ademais, no que diz respeito à concordância verbal, verifica-se a tendência de se fazer a concordância com o elemento nominal (parte do SN-sujeito) mais próximo do sintagma verbal (SV).

\title{
Exemplos 1
}

a. $\quad *[\ldots]$ as nossas sinceras desculpa...( NHATUVE; FONSECA, 2013).

b. $\quad{ }^{*}[\ldots]$ autores mais importante... (NHATUVE; FONSECA, 2013).

c. $\quad *[\ldots]$ a gastronomia exótico...(NHATUVE; FONSECA, 2013).

d. $\quad *[\ldots]$ quando eles apresentar o programa...(NHATUVE; FONSECA, 2013).

e. $\quad{ }^{*}$ A delimitação das fronteiras [...] facilitam o melhor aproveitamento dos recursos (NHATUVE; FONSECA, 2013).

\section{b) Uso de artigos}

No que tange ao uso dos artigos, a variedade moçambicana de Português caracteriza-se por: 1. tendência para omissão do artigo (exemplos 2a, 2b) - no corpus analisado por Gonçalves (1997, p. 57), cerca de 80\% dos desvios têm a ver com esta tendência; 2 . uso do quantificador universal todo e do dual ambos sem artigos ou demonstrativos (exemplos 2c, 2d); 3. ausência de artigos ou demonstrativos a precederem os possessivos (exemplos 2e, 2f); e 4. uso de preposições com complementos nominais sem artigos (exemplos 2g, 2h) (ATANÁSIO, 2002, p. 110-112).

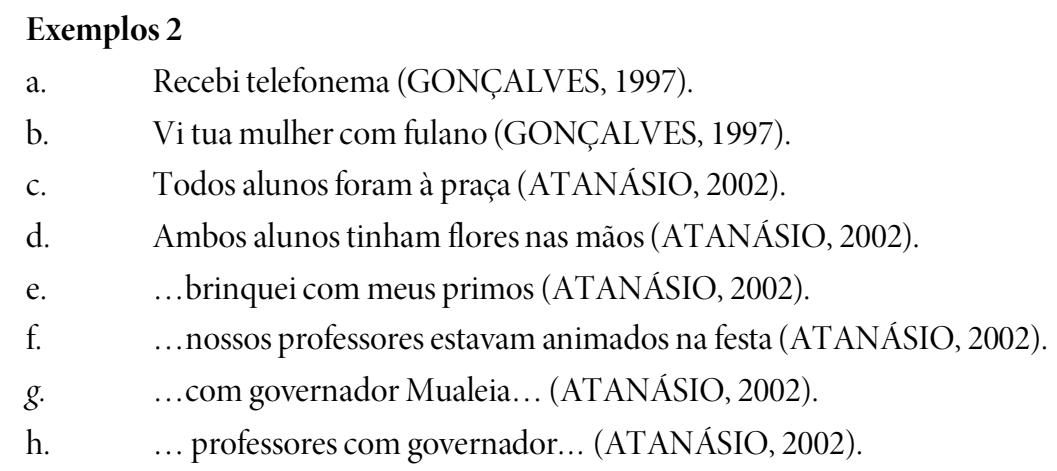

\section{c) Articulação de orações relativas}

$\mathrm{Na}$ articulação de orações, a subordinação relativa apresenta características peculiares no PM (NHATUVE; FONSECA, 2013, p. 145-156). Os verbos preposicionados tais como gostar de, falar de, discutir com, referir-se a, viver com etc. (NHATUVE; FONSECA, 2013), quando integrados em orações que se articulam com outras por meio de pronomes relativos, perdem as suas preposições ou a preposição usada é inadequada (exemplos 3a, 3b, 3c), conforme Gonçalves et al. (1998, p. 98). E, para além da omissão da preposição (parte do verbo), fica claro o uso do que como um relativo universal, independentemente da semântica do elemento representado (exemplos 3a, 3b e 3c). Brito (2002, p. 303), por sua vez, num estudo sobre o uso do relativo cujo no PM revela os seguintes casos: 1. relativas de cujo e o determinante demonstrativo esse; 2. relativas de cujo e o artigo definido; 3 . relativas de cujo e o determinante possessivo seu etc. (exemplos 3d, 3e, 3f).

\author{
Exemplos 3 \\ a. A casa que vivo é grande (NHATUVE; FONSECA, 2013). \\ b. A moça que te falei ontem chegou (NHATUVE; FONSECA, 2013). \\ c. A moça que vive o Plebe é Loira (NHATUVE; FONSECA, 2013). \\ d. Vai entrar onde que a gente dorme (GONÇALVES et al., 1998). \\ e. Recebi uma proposta por escrito cuja essa proposta era desfavorável (GONÇALVES et al., 1998). \\ f. Tenho uma amiga que acontece a mesma coisa com ela (GONÇALVES et al., 1998).
}




\title{
d) Construção de passivas
}

Na construção das passivas sintáticas, processo que se resume na transformação dos constituintes sintáticos, registra-se uma escolha aleatória dos elementos sujeitos à transformação, dando lugar a estruturas como:

\author{
Exemplos 4 \\ a. O Pablo foi oferecido um livro pelo João (NHATUVE; FONSECA, 2013). \\ b. A criança foi nascido no hospital (NHATUVE; FONSECA, 2013). \\ c. O professor foi levado o livro pelo João (NHATUVE; FONSECA, 2013).
}

\section{e) Uso dos clíticos}

A pronominalização também apresenta aspectos particulares tais como a lheização $o^{6}$ a comutação da forma de objeto direto (OD) de terceira pessoa pela forma de sujeito e a seleção de formas pronominais de OD não previstas no PE em função da terminação verbal ( GONÇALVES, 1996a, p. 313-322).

\author{
Exemplos 5 \\ a. Eu não ajudava a ela (GONÇALVES et al., 1998). \\ b. $\quad$ Levam a miúda para o quarto, vestem-lhe (GONÇALVES et al., 1998). \\ c. O João viu ela... (NHATUVE; FONSECA, 2013).
}

\subsection{REGÊNCIA}

No que diz respeito à regência verbal, notam-se três aspectos, a saber: a dificuldade de identificação do argumento interno selecionado pelo verbo, a transitivização dos verbos e a nominalização dos argumentos (GONÇALVES, 1998), dando origem a enunciados como:

\author{
Exemplos 5 \\ a. Eu gosto a Maria (NHATUVE; FONSECA, 2013). \\ b. $\quad$ Ela confia o marido (NHATUVE; FONSECA, 2013). \\ c. [...] responder o desafio do momento (NHATUVE; FONSECA, 2013).
}

Enquanto no PE os verbos Gostar (a), confiar (b) e responder (c) selecionam um complemento nominal preposicionado - eu gosto da Maria; b. ela confia no marido e c. [...] responder aos desafios do momento - os exemplos do PM revelam a colocação dos SNs - a Maria; o marido; o desafio - no lugar dos sintagmas preposicionais (SPs).

\section{NORMATIZAR O PM: CONTRIBUTOS}

Internamente, a discussão sobre a necessidade e a possibilidade de normatização do PM conta algumas décadas, porém continua atualíssima. Envolvem-se na discussão linguistas, professores bem como cidadãos comuns, mas nenhuma das contribuições, embora opostas, conduziu a uma prática objetiva de e para a padronização do PM. No capítulo II de A Génese do Português de Moçambique, Gonçalves (2010) descreve sucintamente os aspetos lexicais, morfológicos e sintáticos que caracterizam o PM.

No ponto 3 do mesmo capítulo, Gonçalves (2010) faz uma pequena resenha sobre a padronização do PM, na qual a súmula é a convergência de vários autores pró padronização do PM, partindo dos seus aspectos salientes e estudados; no entanto, a autora alerta para o fato de ainda não terem sido feitos estudos em todas as áreas - faltam estudos nas áreas da fonética, da fonologia, da semântica e de estratégias retórico-discursivas - que marcam o PM, de modo a avançar-se com a padronização sem sobressaltos. Num outro

${ }^{6} \mathrm{O}$ termo lheização é usado para se referir ao uso do pronome lhe para representar o objeto direto de uma frase. 
estudo, Gonçalves (2005, p. 193) revela que ainda não se fez uma descrição suficiente da "variedade educada" do PM. Efetivamente, não devendo a norma do PM refletir e legitimar necessariamente os usos desviantes (em relação ao PE), fruto de baixa escolarização, o fato apela para o empenho também no estudo e descrição da variedade educada.

Deste modo, está claro que, no que concerne ao processo de normatização (quando se deve começar, aspetos a considerar etc.), encontram-se e divergem três alas: (1) a dos que defendem a padronização com base nos aspectos evidentes do PM (DIAS, 2002; GONÇALVES, 2010); (2) a dos que defendem a padronização considerando o Português falado pela camada considerada dos falantes do bom português ${ }^{8}$ (LOPES, 1997, p. 45); e (3) a dos que defendem a descrição exaustiva do PM, para só depois poder avançar com a sua padronização (GONÇALVES, 2010). Talvez sejam estas as divergências que desencorajam os linguistas comprometidos com o assunto. No entanto, esperar por uma descrição exaustiva, ainda que esta tenha sua importância, dado que não pode ser feita de um dia para outro, fará com que o processo de normatização do PM seja constantemente adiado, pois o Português, tal como acontece com todas as línguas vivas, sobretudo em contextos como o moçambicano, está em constante mudança.

Aliás,

[...] a situação de contacto constante da [LP] com as línguas do grupo bantu - as Ll's da maior parte dos falantes - torna mais acentuadas e consequentemente mais visíveis as estratégias adotadas pelos locutores na construção da gramática de L2, o Português [...]. Pode pois admitir-se que a gramática do Português/L2 de Moçambique é um sistema de conhecimento estável, constituindo, por conseguinte uma base legítima para a natureza da investigação que realizámos (GONÇALVES, 1996b, p. 37-38).

Ora, tornando-se mais “[...] visíveis as estratégias adotadas pelos locutores" (falantes moçambicanos) no uso da LP, entendendo que a respectiva gramática constitui um “[...] sistema de conhecimento estável” (GONÇALVES, 1996b, p. 37-38), os aspectos principais que faltam para o início da normatização do PM são o trabalho de linguistas e uma política linguística favoráveis a esse Português falado por moçambicanos. Considerar apenas o Português falado pelas elites - "[...] falantes do bom português” (DIAS, 2002, p. 192) -, num território como Moçambique, cujas classes da elite são constituídas por uma minoria entre moçambicanos e estrangeiros, incorre na obtenção de dados ilusórios que poderão continuar a divergir com os falares típicos da maioria dos moçambicanos. Aliás, estas elites, na sua maioria, continuam obcecadas a lutarem por falar como portugueses.

A sobrevivência do Português em Moçambique depende sobremaneira do processo de escolarização. Entretanto, dadas as condições socioeconômicas do país, o acesso à educação continua muito aquém do ideal. De acordo com os dados do Instituto Nacional de Estatística (2015, p. 5-21), dos cerca de 25.041.922 de habitantes, 49.9\% (taxa de analfabetismo) não sabem ler e escrever. As descrições que têm sido feitas e que evidenciam vários aspectos do PM são feitas em todas as camadas (menos instruídas - mais instruídas), no entanto, os dados pontuais que se evidenciam são os da menos instruída. Por isso, considerar simplesmente os dados evidentes também pode conduzir a um equívoco. Trata-se, na linguagem de Dias (2002), da variante misturada, "[...] fruto de maior contato da LP e as línguas bantu” ( p. 179).

A discussão sobre a padronização do PM é bastante renhida, envolvendo também a questão da nativização do Português. Porém, está claro que não são os aspectos relacionados com o sentido de pertença do Português aos moçambicanos, nem é a insuficiência de aspectos característicos do PM que inviabilizam a sua normatização. Talvez falte, reitere-se, o trabalho e os incentivos morais, profissionais, etc. Indignado com a situação, Lopes (1997) critica severamente esta situação:

A língua - falada e imprensa - utilizada entre nós é diferente do 'português mãe'. Considero uma futilidade ter de esperar por descrições exaustivas a longo prazo para poder qualificar a nova variedade como PM [...]. O meu ponto de vista é que a variedade do PM adquiriu já um estatuto ontológico, independentemente do estado atual da sua descrição (LOPES, 1997, p. 41-42).

${ }^{7}$ Considera-se variedade educada a variedade do Português falada pela camada culta (jornalistas, escritores, políticos, professores), com altos níveis de escolaridade.

${ }^{8}$ Considera-se bom português a variedade educada, a que se aproxima à variante europeia. 
Considerando que “[...] o português vem sendo modificado na pronúncia, gramática e discurso” (LOPES, 1997, p. 40), e que a competência comunicativa em Português depende da escolarização, propomos, para a normatização do PM, a consideração dos aspectos comuns entre os falantes com escolarização média e os com escolarização avançada. Trata-se de, através da comparação de usos, isolar os aspectos comuns (verdadeiras marcas do PM) entre os dois grupos e prescrevê-los. Seria aquela variante dos considerados bons falantes, mas que não negligencia os falares que tipificam o PM, ou seja, contém aspectos que, independentemente da instrução, prevalecem típicos do PM. Aquela variante da elite que, de acordo com Dias,

[...] contém certas 'nuances' moçambicanas, como por exemplo, o uso do domínio familiar e oral, de empréstimo das línguas bantu, a utilização de inovações lexicais semelhantes à das variedades misturadas, a manutenção de certas tendências articulatórias muito generalizadas, como por exemplo, a abertura das prétónicas [a e o], a não-realização da metafonia e o uso de padrões repetitivos indicativos de intensidade e de duração, etc. (2002, p.192).

Obviamente, é indiscutível a pertinência da descrição da língua para o sucesso da sua prescrição: as “[...] questões que se relacionam com a padronização [do PM] só podem ser completamente resolvidas quando for feita a descrição exaustiva” (LOPES, 1997, p. 4). No entanto, ficar à espera da descrição total pode ser fatal. A descrição e a normatização, em termos linguísticos, têm de ser um processo contínuo até que se atinja um nível estável (em que estejam previstos todos os aspectos que particularizam o PM).

Com efeito, a normatização do PM teria incontestavelmente um impacto benéfico aos seus falantes. O PMé uma variante não nativa e parece difícil contornar as marcas das LMs da maioria dos falantes, sendo, por isso, visto preconceituosamente como fruto da incapacidade dos falantes de aprender o considerado "bom português"; assim, todo o tipo de desvio constitui motivo de depreciação (GONÇALVES, 2010, p. 14).

Portanto, a normatização do falar comum de um povo - legitimação das realizações linguísticas que caracterizam os moçambicanos - acabará com todas as interpretações pessimistas do modo de falar tipicamente moçambicano e promoverá a autoestima linguística dos falantes. Para além disto, a normatização do PM legitimará os falares que têm espaço no país, o que inequivocamente, facilitará o seu estudo. Mais do que isso, contrariamente ao que se pode pensar, constituirá o reconhecimento do caráter dinâmico e da evolução do Português.

\section{CONCLUSÃO}

O PM atingiu níveis de variação na maior parte dos principais aspectos linguísticos: morfológicos, sintáticos, lexicais, morfossintáticos, fonéticos, fonológicos etc.; todavia, ainda não é objeto de uma normatização. A discussão acerca deste assunto opõe vários linguistas: uns defendem a necessidade e a possibilidade de normatização do PM, outros consideram que ainda é cedo para tal processo. No entanto, sendo verdade que os aspectos que particularizam o PM são claramente evidentes, constituindo um conhecimento relativamente estável, é legítimo que se comece o trabalho da sua normatização.

Este processo não deve simplesmente considerar os aspectos do PM até aqui revelados por grande parte dos investigadores, pois, na sua maioria, são ultrapassados com o processo de escolarização; nem simplesmente os aspectos do Português das elites, pois estes constituem uma minoria e não refletem melhor a variedade moçambicana do Português. Portanto, a norma do PM deve basear-se nos aspectos que se registram quer na camada de falantes médios, quer na de falantes educados/cultos (falantes do bom português) - pois é isto que constitui as verdadeiras marcas do PM. Isto implica considerar os aspectos que sobrevivem mesmo com o processo de instrução. Naturalmente, a normatização não deve negligenciar a descrição, mas não deve estar refém da descrição exaustiva. Uma norma do PM irá acabar com as inconveniências que se associam às línguas não nativas, por isso, recomenda-se. 


\section{REFERÊNCIAS}

ATANÁSIO, N. Ausência do artigo no Português de Moçambique: análise de um corpus constituído por textos de alunos do ensino básico em Nampula. 2002. 176f. Dissertação (Mestrado em Linguística Portuguesa) - Universidade do Porto e Universidade Pedagógica, Nampula, 2002.

BRITO, A. M. Relativas de genitivo "estranhas" no português de Moçambique: erros ou sinais de mudança? Porto: Universidade do Porto - Faculdade de Letras, 2002. Disponível em: <http://ler.letras.up.pt/uploads/ficheiros/7123.pdf.>. Acesso em: 22 out. 2016.

CARNEIRO, R. A educação intercultural. In MATOS, Artur Teodoro de; LAGES, Mário F.. Povos e Culturas - No 13: Portugal Intercultural. Lisboa: Centro de Estudos dos Povos e Culturas de Expressão Portuguesas, 2009. p. 129-178.

DIAS, H. N. As desiguldades sociolinguísticas e ofracasso escolar. Maputo: Promídia, 2002.

DUARTE, I. Língua Portuguesa: instrumentos de análise. Lisboa: Universidade Aberta, 2000.

FERREIRA, M. Numa perspectiva sociocultural. Que futuro para a Língua Portuguesa em África? In: CINTRA, Luís. F. L. (Org.). Congresso sobre a situação actual da Língua Portuguesa no mundo. Lisboa: ICALP, 1987. p. 248-272.

FERREIRA, M. B. et al. Variação linguística: perspectiva dialectológica. In: FARIA, Isabel. et al. (Org.). Introdução à linguística geral e portuguesa. Lisboa: Caminho, 1996.

FIRMINO, G. Aspectos da nacionalização do português de Moçambique. Veredas: revista da Associação Internacional de Lusitanistas, Porto Alegre, v. 9, p. 115-135, 2008. Disponível em: <http://hdl.handle.net/10316.2/34455>. Acesso: 29 out. 2016.

GONÇALVES P. et al. Estruturas gramaticais do português: problemas e exercícios. In: GONÇALVES, Perpétua; STROUD, Christopher. (Org.). Panorama do português oral de Maputo. v. 3. Maputo: INDE, 1998. p. 36-139.

GONÇALVES, P. Aspectos da sintaxe do português de Moçambique. In: FARIA, Isabel. et al. (Org.). Introdução à linguística geral e portuguesa. Lisboa: Caminho, 1996a. p. 313-322.

. Tipologia de 'erros' do português oral de Maputo. In: STROUD, Christopher; GONÇALVES, Perpétua (Org.). Panorama do português oral de Maputo: A construção de um banco de "erros". v. 2. Maputo: Instituto Nacional do Desenvolvimento da Educação, 1998. p. 37-67.

Português de Moçambique: problemas e limites de padronização de uma variante não-nativa. In: SINNER, Carsten. (Ed.). Norm und Normkonflikte in der Romanian. Munich: Peniopel, 2005. p.184-195.

A génese do português de Moçambique. Lisboa: Imprensa Nacional-Casa da Moeda, S.A, 2010.

Português de Moçambique: uma variedade em formação. Maputo: Livraria Universitária-UEM, $1996 \mathrm{~b}$.

INSTITUTO NACIONAL DE ESTATÍSTICA. Anuário estatístico 2014-Moçambique. Maputo: Instituto Nacional de Estatística, 2015. 
LOPES, A. J. Política linguística: princípios e problemas. Maputo: Livraria Universitária-UEM, 1997.

MATEUS, M. H. M.; VILALVA, A. Linguística. Lisboa: Caminho, 2007.

MATEUS, M. H. M; CARDEIRA E. Norma e variação. Lisboa: Caminho, 2007.

NHATUVE, D. J. R.; FONSECA, M. C. Aspectos da sintaxe do português falado no sul de Moçambique. Revista de Letras, Vila Real, série II, n. 11, p. 145-156, 2013.

SANTANA, B. P. A difusão da língua portuguesa no contexto multilingue Moçambicano. In: MARÇALO, Maria João et al. (Ed.). Língua portuguesa: ultrapassar fronteiras, juntar culturas. Évora: Universidade de Évora, 2010. p. 58-70. ISBN: 978-972-99292-4-3. Disponível em <http://www.simelp2009.uevora.pt/pdf/slg6/07.pdf>. Acesso em: 04 dez. 2012. 